\title{
Asymptotic behavior of a third-order nonlinear neutral delay differential equation
}

Ying Jiang ${ }^{1}$ and Tongxing $\mathrm{Li}^{2,3 *}$

${ }^{\text {*Correspondence: }}$
litongx2007@163.com
${ }^{2}$ LinDa Institute of Shandong
Provincial Key Laboratory of
Network Based Intelligent
Computing, Linyi University, Linyi,
Shandong 276005, P.R. China
${ }^{3}$ School of Informatics, Linyi
University, Linyi, Shandong 276005,
P.R. China
Full list of author information is
available at the end of the article

available at the end of the article

\begin{abstract}
The objective of this paper is to study asymptotic nature of a class of third-order neutral delay differential equations. By using a generalized Riccati substitution and the integral averaging technique, a new Philos-type criterion is obtained which ensures that every solution of the studied equation is either oscillatory or converges to zero. An illustrative example is included.
\end{abstract}

MSC: $34 \mathrm{~K} 11$

Keywords: asymptotic behavior; third-order neutral differential equation; oscillation; generalized Riccati substitution

\section{Introduction}

In this work, we study the oscillation and asymptotic behavior of a third-order nonlinear neutral differential equation with variable delay arguments

$$
\left(r(t)[x(t)+P(t) x(t-\tau(t))]^{\prime \prime}\right)^{\prime}+\sum_{i=1}^{m} Q_{i}(t) f_{i}\left(x\left(t-\sigma_{i}(t)\right)\right)=0, \quad t \geq t_{0},
$$

where $m \geq 1$ is an integer and $t_{0}>0$. We assume that the following hypotheses are satisfied.

(A $\left.\mathrm{A}_{1}\right) r \in \mathrm{C}^{1}\left(\left[t_{0}, \infty\right),(0, \infty)\right), P, \tau, Q_{i}, \sigma_{i} \in \mathrm{C}\left(\left[t_{0}, \infty\right),[0, \infty)\right), f_{i} \in \mathrm{C}(\mathbb{R}, \mathbb{R})$, and $u f_{i}(u)>0$ for

$$
u \neq 0, i=1,2, \ldots, m \text {; }
$$

$\left(\mathrm{A}_{2}\right) \quad r^{\prime}(t) \geq 0, \int_{t_{0}}^{\infty} r^{-1}(t) \mathrm{d} t=\infty$, and $0 \leq P(t) \leq p_{0}<1$;

$\left(\mathrm{A}_{3}\right) \lim _{t \rightarrow \infty}(t-\tau(t))=\lim _{t \rightarrow \infty}\left(t-\sigma_{i}(t)\right)=\infty, i=1,2, \ldots, m$;

$\left(\mathrm{A}_{4}\right)$ there exist constants $\alpha_{i}>0$ such that $f_{i}(u) / u \geq \alpha_{i}$ for $u \neq 0$ and $i=1,2, \ldots, m$.

Throughout, we define

$$
z(t):=x(t)+P(t) x(t-\tau(t))
$$

By a solution of equation (1), we mean a function $x \in \mathrm{C}\left(\left[T_{x}, \infty\right), \mathbb{R}\right), T_{x} \geq t_{0}$, which has the properties $z \in C^{2}\left(\left[T_{x}, \infty\right), \mathbb{R}\right), r z^{\prime \prime} \in C^{1}\left(\left[T_{x}, \infty\right), \mathbb{R}\right)$, and satisfies $(1)$ on $\left[T_{x}, \infty\right)$. We consider only those solutions $x$ of (1) which satisfy assumption $\sup \{|x(t)|: t \geq T\}>0$ for all $T \geq T_{x}$. We assume that (1) possesses such solutions. A solution of (1) is called oscillatory if it has arbitrarily large zeros on $\left[T_{x}, \infty\right)$; otherwise, it is termed nonoscillatory.

\section{Springer}

@2014 Jiang and Li; licensee Springer. This is an Open Access article distributed under the terms of the Creative Commons Attribution License (http://creativecommons.org/licenses/by/2.0), which permits unrestricted use, distribution, and reproduction in any medium, provided the original work is properly cited. 
As is well known, the third-order differential equations are derived from many different areas of applied mathematics and physics, for instance, deflection of buckling beam with a fixed or variable cross-section, three-layer beam, electromagnetic waves, gravity-driven flows, etc. In recent years, the oscillation theory of third-order differential equations has received a great deal of attention since it has been widely applied in research of physical sciences, mechanics, radio technology, lossless high-speed computer network, control system, life sciences, and population growth.

Numerous research activities are concerned with the oscillation of solutions to different functional differential equations, for some related contributions, we refer the reader to [1-16] and the references cited therein. In the following, we provide some background details regarding the study of various classes of neutral differential equations. Baculíková and Džurina [3] studied a second-order neutral differential equation

$$
\left(r(t)[x(t)+p(t) x(\tau(t))]^{\prime}\right)^{\prime}+q(t) x(\sigma(t))=0 .
$$

Agarwal et al. [1], Grace et al. [7], and Zhang et al. [16] considered a third-order nonlinear differential equation

$$
\left(a(t)\left(b(t) x^{\prime}(t)\right)^{\prime}\right)^{\prime}+q(t) x^{\gamma}(\sigma(t))=0 .
$$

Baculíková and Džurina [4], Candan [5, 6], Karpuz [8], Li and Rogovchenko [9], Li and Thandapani [10], and Li et al. [11,12] investigated a class of third-order neutral differential equations

$$
\left(r(t)[x(t)+p(t) x(\tau(t))]^{\prime \prime}\right)^{\prime}+q(t) x(\sigma(t))=0 .
$$

Define $\tilde{\tau}(t):=t-\tau(t)$ and $\tilde{\sigma}_{i}(t):=t-\sigma_{i}(t), i=1,2, \ldots, m$. It follows from conditions $\left(\mathrm{A}_{1}\right)$ and $\left(\mathrm{A}_{3}\right)$ that $\tilde{\tau}(t) \leq t, \tilde{\sigma}_{i}(t) \leq t$, and $\lim _{t \rightarrow \infty} \tilde{\tau}(t)=\lim _{t \rightarrow \infty} \tilde{\sigma}_{i}(t)=\infty, i=1,2, \ldots, m$. Hence, equation (3) is a special case of (1). As a matter of fact, equation (1) reduces to the form of (3) if $m=1$ and $f_{1}(u)=u$.

There are two techniques in the study of oscillation of third-order neutral differential equations. One of them is comparison method which is used to reduce the third-order neutral differential equations to the first-order differential equations or inequalities; see, e.g., [8-10]. Another technique is the Riccati technique; see, e.g., [4-6, 10-12]. In this paper, using a generalized Riccati substitution which differs from those reported in [4-6, 10-12], a new asymptotic criterion for (1) is presented. In what follows, all functional inequalities are tacitly supposed to hold for all sufficiently large $t$.

\section{Some lemmas}

Lemma 1 Assume that conditions $\left(\mathrm{A}_{1}\right)-\left(\mathrm{A}_{4}\right)$ hold and $x$ is a positive solution of $(1)$. Then there are only the following two possible cases for $z$ defined by (2):

(I) $z(t)>0, z^{\prime}(t)>0, z^{\prime \prime}(t)>0, z^{\prime \prime \prime}(t) \leq 0$, and $\left(r(t) z^{\prime \prime}(t)\right)^{\prime} \leq 0$;

(II) $z(t)>0, z^{\prime}(t)<0, z^{\prime \prime}(t)>0, z^{\prime \prime \prime}(t) \leq 0$, and $\left(r(t) z^{\prime \prime}(t)\right)^{\prime} \leq 0$, for $t \geq T$, where $T \geq t_{0}$ is sufficiently large.

Proof The proof is similar to that of Baculíková and Džurina [4, Lemma 1], and hence is omitted. 
Lemma 2 Assume that conditions $\left(\mathrm{A}_{1}\right)-\left(\mathrm{A}_{4}\right)$ hold and let $x$ be a positive solution of $(1)$ and corresponding $z$ satisfy case (II) in Lemma 1 . If

$$
\int_{t_{0}}^{\infty} \int_{v}^{\infty} \frac{1}{r(u)}\left(\sum_{i=1}^{m} \int_{u}^{\infty} Q_{i}(s) \mathrm{d} s\right) \mathrm{d} u \mathrm{~d} v=\infty
$$

then $\lim _{t \rightarrow \infty} x(t)=\lim _{t \rightarrow \infty} z(t)=0$.

Proof Suppose that $x$ is a positive solution of (1). Since $z(t)>0$ and $z^{\prime}(t)<0$, there exists a finite constant $l \geq 0$ such that $\lim _{t \rightarrow \infty} z(t)=l \geq 0$. We shall prove that $l=0$. Assume now that $l>0$. Then for any $\varepsilon>0$, there exists a $t_{1} \geq T$ such that $l+\varepsilon>z(t)>l$ for $t \geq t_{1}$. Choose $0<\varepsilon<l\left(1-p_{0}\right) / p_{0}$. It is not hard to find that

$$
\begin{aligned}
x(t) & =z(t)-P(t) x(t-\tau(t))>l-P(t) x(t-\tau(t))>l-p_{0} z(t-\tau(t)) \\
& >l-p_{0}(l+\varepsilon):=N(l+\varepsilon)>N z(t),
\end{aligned}
$$

where $N:=\left(l-p_{0}(l+\varepsilon)\right) /(l+\varepsilon)>0$. Using (1) and (5), we conclude that

$$
\begin{aligned}
0 & =\left(r(t) z^{\prime \prime}(t)\right)^{\prime}+\sum_{i=1}^{m} Q_{i}(t) f_{i}\left(x\left(t-\sigma_{i}(t)\right)\right) \\
& \geq\left(r(t) z^{\prime \prime}(t)\right)^{\prime}+\sum_{i=1}^{m} \alpha_{i} Q_{i}(t) x\left(t-\sigma_{i}(t)\right) \\
& \geq\left(r(t) z^{\prime \prime}(t)\right)^{\prime}+N \sum_{i=1}^{m} \alpha_{i} Q_{i}(t) z\left(t-\sigma_{i}(t)\right) \\
& \geq\left(r(t) z^{\prime \prime}(t)\right)^{\prime}+N \sum_{i=1}^{m} \alpha_{i} Q_{i}(t) z(t) .
\end{aligned}
$$

Integrating (6) from $t$ to $\infty$, we obtain

$$
0 \geq-r(t) z^{\prime \prime}(t)+N \sum_{i=1}^{m} \alpha_{i} \int_{t}^{\infty} Q_{i}(s) z(s) \mathrm{d} s
$$

Noting that $z(t)>l$, we get

$$
0 \geq-z^{\prime \prime}(t)+\frac{l N}{r(t)} \sum_{i=1}^{m} \alpha_{i} \int_{t}^{\infty} Q_{i}(s) \mathrm{d} s
$$

Integrating (7) from $t$ to $\infty$, we have

$$
0 \geq z^{\prime}(t)+l N \int_{t}^{\infty} \frac{1}{r(u)}\left(\sum_{i=1}^{m} \alpha_{i} \int_{u}^{\infty} Q_{i}(s) \mathrm{d} s\right) \mathrm{d} u .
$$

Integrating (8) from $t_{1}$ to $\infty$, we deduce that

$$
\int_{t_{1}}^{\infty} \int_{v}^{\infty} \frac{1}{r(u)}\left(\sum_{i=1}^{m} \alpha_{i} \int_{u}^{\infty} Q_{i}(s) \mathrm{d} s\right) \mathrm{d} u \mathrm{~d} v \leq \frac{z\left(t_{1}\right)}{l N},
$$


which contradicts (4). Hence, $l=0$ and $\lim _{t \rightarrow \infty} z(t)=0$. Then it follows from $0 \leq x(t) \leq$ $z(t)$ that $\lim _{t \rightarrow \infty} x(t)=0$. The proof is complete.

Lemma 3 (See [4, Lemma 3]) Assume that $u(t)>0, u^{\prime}(t)>0$, and $u^{\prime \prime}(t) \leq 0$ for $t \geq t_{0}$. If $\sigma \in \mathrm{C}\left(\left[t_{0}, \infty\right),[0, \infty)\right), \sigma(t) \leq t$, and $\lim _{t \rightarrow \infty} \sigma(t)=\infty$, then for every $\alpha \in(0,1)$, there exists a $T_{\alpha} \geq t_{0}$ such that $u(\sigma(t)) / \sigma(t) \geq \alpha u(t) / t$ for $t \geq T_{\alpha}$.

Remark 1 If $u$ satisfies conditions of Lemma 3, then $u\left(t-\sigma_{i}(t)\right) / u(t) \geq \alpha\left(t-\sigma_{i}(t)\right) / t$ for $i=1,2, \ldots, m$ when using conditions $\left(\mathrm{A}_{1}\right)$ and $\left(\mathrm{A}_{3}\right)$.

Lemma 4 (See [4, Lemma 4]) Assume that $u(t)>0, u^{\prime}(t)>0, u^{\prime \prime}(t)>0$, and $u^{\prime \prime \prime}(t) \leq 0$ for $t \geq t_{0}$. Then for each $\beta \in(0,1)$, there exists a $T_{\beta} \geq t_{0}$ such that $u(t) \geq \beta$ tu' $(t) / 2$ for $t \geq T_{\beta}$.

Remark 2 If $u$ satisfies conditions of Lemma 4, then $u\left(t-\sigma_{i}(t)\right) / u^{\prime}\left(t-\sigma_{i}(t)\right) \geq \beta(t-$ $\left.\sigma_{i}(t)\right) / 2$ for $i=1,2, \ldots, m$ when using condition $\left(\mathrm{A}_{3}\right)$.

\section{Main results}

We use the integral averaging technique to establish a Philos-type (see Philos [13]) criterion for (1). Let

$$
\mathbb{D}:=\left\{(t, s): t \geq s \geq t_{0}\right\} \quad \text { and } \quad \mathbb{D}_{0}:=\left\{(t, s): t>s \geq t_{0}\right\} .
$$

We say that a function $H \in \mathrm{C}(\mathbb{D}, \mathbb{R})$ belongs to the class $X$ if

(i) $H(t, t)=0, t \geq t_{0}, H(t, s)>0,(t, s) \in \mathbb{D}_{0}$;

(ii) $H$ has a nonpositive continuous partial derivative $\partial H / \partial s$ on $\mathbb{D}_{0}$ with respect to the second variable, and there exist functions $\rho \in \mathrm{C}^{1}\left(\left[t_{0}, \infty\right),(0, \infty)\right), \delta \in \mathrm{C}^{1}\left(\left[t_{0}, \infty\right), \mathbb{R}\right)$, and $h \in \mathrm{C}\left(\mathbb{D}_{0}, \mathbb{R}\right)$ such that

$$
\frac{\partial H(t, s)}{\partial s}+\left(2 \delta(s)+\frac{\rho^{\prime}(s)}{\rho(s)}\right) H(t, s)=-h(t, s) \sqrt{H(t, s)} .
$$

Theorem 1 Assume that conditions $\left(\mathrm{A}_{1}\right)-\left(\mathrm{A}_{4}\right)$ and (4) are satisfied. If

$$
\limsup _{t \rightarrow \infty} \frac{1}{H\left(t, t_{0}\right)} \int_{t_{0}}^{t}\left[H(t, s) G(s)-\frac{1}{4} \rho(s) r(s) h^{2}(t, s)\right] \mathrm{d} s=\infty
$$

holds for some $\alpha \in(0,1), \beta \in(0,1)$, and for some $H \in X$, where

$$
G(t):=\rho(t)\left[\frac{\alpha \beta\left(1-p_{0}\right)}{2} \sum_{i=1}^{m} \alpha_{i} Q_{i}(t) \frac{\left(t-\sigma_{i}(t)\right)^{2}}{t}+r(t) \delta^{2}(t)-(r(t) \delta(t))^{\prime}\right],
$$

then every solution $x$ of $(1)$ is either oscillatory or satisfies $\lim _{t \rightarrow \infty} x(t)=0$.

Proof Suppose to the contrary and assume that (1) has a nonoscillatory solution $x$. Without loss of generality, we can assume that there exists a $t_{1} \geq t_{0}$ such that $x(t)>0, x(t-\tau(t))>$ 0 , and $x\left(t-\sigma_{i}(t)\right)>0$ for $t \geq t_{1}$ and $i=1,2, \ldots, m$. By Lemma 1 , we observe that $z$ satisfies either (I) or (II) for $t \geq T$, where $T \geq t_{1}$ is large enough. We consider each of the two cases separately. 
Assume first that case (I) holds. It follows from $z^{\prime}(t)>0$ that

$$
\begin{aligned}
x(t) & =z(t)-P(t) x(t-\tau(t)) \geq z(t)-p_{0} x(t-\tau(t)) \\
& \geq z(t)-p_{0} z(t-\tau(t)) \geq\left(1-p_{0}\right) z(t) .
\end{aligned}
$$

Using (1) and (12), we deduce that

$$
\begin{aligned}
\left(r(t) z^{\prime \prime}(t)\right)^{\prime} & =-\sum_{i=1}^{m} Q_{i}(t) f_{i}\left(x\left(t-\sigma_{i}(t)\right)\right) \\
& \leq-\sum_{i=1}^{m} \alpha_{i} Q_{i}(t) x\left(t-\sigma_{i}(t)\right) \\
& \leq-\left(1-p_{0}\right) \sum_{i=1}^{m} \alpha_{i} Q_{i}(t) z\left(t-\sigma_{i}(t)\right) .
\end{aligned}
$$

Define a generalized Riccati substitution by

$$
\omega(t):=\rho(t)\left[\frac{r(t) z^{\prime \prime}(t)}{z^{\prime}(t)}+r(t) \delta(t)\right]
$$

Then we have

$$
\begin{aligned}
\omega^{\prime} & =\rho^{\prime}\left[\frac{r z^{\prime \prime}}{z^{\prime}}+r \delta\right]+\rho\left[\frac{r z^{\prime \prime}}{z^{\prime}}+r \delta\right]^{\prime} \\
& =\frac{\rho^{\prime}}{\rho} \omega+\rho(r \delta)^{\prime}+\rho\left(\frac{r z^{\prime \prime}}{z^{\prime}}\right)^{\prime} \\
& =\frac{\rho^{\prime}}{\rho} \omega+\rho(r \delta)^{\prime}+\rho \frac{\left(r z^{\prime \prime}\right)^{\prime}}{z^{\prime}}-\rho r\left(\frac{z^{\prime \prime}}{z^{\prime}}\right)^{2} .
\end{aligned}
$$

By virtue of (14), we conclude that

$$
\left(\frac{z^{\prime \prime}}{z^{\prime}}\right)^{2}=\left[\frac{\omega}{\rho r}-\delta\right]^{2}=\left(\frac{\omega}{\rho r}\right)^{2}+\delta^{2}-2 \frac{\omega \delta}{\rho r} .
$$

Substituting (13) and (16) into (15), we obtain

$$
\begin{aligned}
\omega^{\prime} & =\rho \frac{\left(r z^{\prime \prime}\right)^{\prime}}{z^{\prime}}+\frac{\rho^{\prime}}{\rho} \omega+\rho(r \delta)^{\prime}-\rho r\left[\frac{\omega^{2}}{\rho^{2} r^{2}}+\delta^{2}-2 \frac{\omega \delta}{\rho r}\right] \\
& =\rho \frac{\left(r z^{\prime \prime}\right)^{\prime}}{z^{\prime}}-\rho\left[r \delta^{2}-(r \delta)^{\prime}\right]+\left(\frac{\rho^{\prime}}{\rho}+2 \delta\right) \omega-\frac{\omega^{2}}{r \rho} \\
& \leq-\left(1-p_{0}\right) \rho \sum_{i=1}^{m} \alpha_{i} Q_{i} \frac{z\left(t-\sigma_{i}(t)\right)}{z^{\prime}(t)}-\rho\left[r \delta^{2}-(r \delta)^{\prime}\right]+\left(\frac{\rho^{\prime}}{\rho}+2 \delta\right) \omega-\frac{\omega^{2}}{r \rho}
\end{aligned}
$$

It follows from Remarks 1 and 2 that, for any $\alpha \in(0,1)$ and $\beta \in(0,1)$,

$$
\frac{z\left(t-\sigma_{i}(t)\right)}{z^{\prime}(t)}=\frac{z\left(t-\sigma_{i}(t)\right)}{z^{\prime}\left(t-\sigma_{i}(t)\right)} \frac{z^{\prime}\left(t-\sigma_{i}(t)\right)}{z^{\prime}(t)} \geq \frac{\alpha \beta}{2} \frac{\left(t-\sigma_{i}(t)\right)^{2}}{t},
$$


$i=1,2, \ldots, m$. Combining (17) and (18), we get

$$
\begin{aligned}
\omega^{\prime}(t) \leq & -\frac{\alpha \beta\left(1-p_{0}\right)}{2} \rho(t) \sum_{i=1}^{m} \alpha_{i} Q_{i}(t) \frac{\left(t-\sigma_{i}(t)\right)^{2}}{t} \\
& -\rho(t)\left[r(t) \delta^{2}(t)-(r(t) \delta(t))^{\prime}\right]+\left(\frac{\rho^{\prime}(t)}{\rho(t)}+2 \delta(t)\right) \omega(t)-\frac{\omega^{2}(t)}{r(t) \rho(t)} \\
= & -G(t)+A(t) \omega(t)-B(t) \omega^{2}(t),
\end{aligned}
$$

where $G$ is defined as in (11), $A(t):=\left(\rho^{\prime}(t) / \rho(t)\right)+2 \delta(t)$, and $B(t):=1 /(r(t) \rho(t))$. Replacing in the latter inequality $t$ with $s$, multiplying both sides by $H(t, s)$ and integrating with respect to $s$ from some $T_{1}\left(T_{1} \geq T\right)$ to $t$, we derive from $H(t, t)=0$ and (9) that

$$
\begin{aligned}
& \int_{T_{1}}^{t} H(t, s) G(s) \mathrm{d} s \\
& \quad \leq \int_{T_{1}}^{t} H(t, s)\left[-\omega^{\prime}(s)+A(s) \omega(s)-B(s) \omega^{2}(s)\right] \mathrm{d} s \\
& \quad=H\left(t, T_{1}\right) \omega\left(T_{1}\right)+\int_{T_{1}}^{t}\left[\left(\frac{\partial H(t, s)}{\partial s}+A(s) H(t, s)\right) \omega(s)-H(t, s) B(s) \omega^{2}(s)\right] \mathrm{d} s \\
& =H\left(t, T_{1}\right) \omega\left(T_{1}\right)-\int_{T_{1}}^{t}\left[h(t, s) \sqrt{H(t, s)} \omega(s)+H(t, s) B(s) \omega^{2}(s)\right] \mathrm{d} s \\
& \quad=H\left(t, T_{1}\right) \omega\left(T_{1}\right)-\int_{T_{1}}^{t}\left(\sqrt{H(t, s) B(s)} \omega(s)+\frac{h(t, s)}{2 \sqrt{B(s)}}\right)^{2} \mathrm{~d} s+\int_{T_{1}}^{t} \frac{h^{2}(t, s)}{4 B(s)} \mathrm{d} s \\
& \quad \leq H\left(t, T_{1}\right) \omega\left(T_{1}\right)+\int_{T_{1}}^{t} \frac{h^{2}(t, s)}{4 B(s)} \mathrm{d} s,
\end{aligned}
$$

and hence

$$
\limsup _{t \rightarrow \infty} \frac{1}{H\left(t, T_{1}\right)} \int_{T_{1}}^{t}\left[H(t, s) G(s)-\frac{1}{4} \rho(s) r(s) h^{2}(t, s)\right] \mathrm{d} s \leq \omega\left(T_{1}\right),
$$

which contradicts condition (10).

Assume now that case (II) holds. By virtue of Lemma $2, \lim _{t \rightarrow \infty} x(t)=0$. This completes the proof.

Corollary 1 The conclusion of Theorem 1 remains intact if condition (10) is replaced by the assumptions

$$
\limsup _{t \rightarrow \infty} \frac{1}{H\left(t, t_{0}\right)} \int_{t_{0}}^{t} H(t, s) G(s) \mathrm{d} s=\infty
$$

and

$$
\limsup _{t \rightarrow \infty} \frac{1}{H\left(t, t_{0}\right)} \int_{t_{0}}^{t} \rho(s) r(s) h^{2}(t, s) \mathrm{d} s<\infty
$$

As an application of Theorem 1, we provide the following example. 
Example 1 For $t \geq 1$, consider a third-order neutral delay differential equation

$$
\left(x(t)+\frac{1}{3} x\left(\frac{t}{3}\right)\right)^{\prime \prime \prime}+t^{-3} x\left(\frac{t}{4}\right)+4 t^{-3} x\left(\frac{t}{2}\right)=0 .
$$

Let $\rho(t)=t, \delta(t)=0$, and $H(t, s)=(t-s)^{2}$. It is not difficult to verify that all assumptions of Theorem 1 are satisfied. Hence, every solution $x$ of (19) is either oscillatory or satisfies $\lim _{t \rightarrow \infty} x(t)=0$. As a matter of fact, one such solution is $x(t)=t^{-1}$.

\section{Competing interests}

The authors declare that they have no competing interests.

\section{Authors' contributions}

Both authors contributed equally to this work. They both read and approved the final version of the manuscript.

\section{Author details}

${ }^{1}$ Qingdao Technological University, Feixian, Shandong 273400, P.R. China. ${ }^{2}$ LinDa Institute of Shandong Provincial Key Laboratory of Network Based Intelligent Computing, Linyi University, Linyi, Shandong 276005, P.R. China. ${ }^{3}$ School of Informatics, Linyi University, Linyi, Shandong 276005, P.R. China.

\section{Acknowledgements}

The authors are grateful to the editors and two anonymous referees for a very thorough reading of the manuscript and for pointing out several inaccuracies. This research is supported by NNSF of P.R. China (Grant No. 61403061) and the AMEP of Linyi University, P.R. China.

Received: 22 September 2014 Accepted: 8 December 2014 Published: 23 Dec 2014

\section{References}

1. Agarwal, RP, Bohner, M, Li, T, Zhang, C: Oscillation of third-order nonlinear delay differential equations. Taiwan. J. Math. 17, 545-558 (2013)

2. Agarwal, RP, Bohner, M, Tang, S, Li, T, Zhang, C: Oscillation and asymptotic behavior of third-order nonlinear retarded dynamic equations. Appl. Math. Comput. 219, 3600-3609 (2012)

3. Baculíková, B, Džurina, J: Oscillation theorems for second-order nonlinear neutral differential equations. Comput. Math. Appl. 62, 4472-4478 (2011)

4. Baculíková, B, Džurina, J: Oscillation of third-order neutral differential equations. Math. Comput. Model. 52, 215-226 (2010)

5. Candan, T: Oscillation criteria and asymptotic properties of solutions of third-order nonlinear neutral differential equations. Math. Methods Appl. Sci. (2014). doi:10.1002/mma.3153

6. Candan, T: Asymptotic properties of solutions of third-order nonlinear neutral dynamic equations. Adv. Differ. Equ. 2014, 35 (2014)

7. Grace, SR, Agarwal, RP, Pavani, R, Thandapani, E: On the oscillation of certain third order nonlinear functional differential equations. Appl. Math. Comput. 202, 102-112 (2008)

8. Karpuz, B: Sufficient conditions for the oscillation and asymptotic behaviour of higher-order dynamic equations of neutral type. Appl. Math. Comput. 221, 453-462 (2013)

9. Li, T, Rogovchenko, Y: Asymptotic behavior of higher-order quasilinear neutral differential equations. Abstr. Appl. Anal. 2014, Article ID 395368 (2014). doi:10.1155/2014/395368

10. Li, T, Thandapani, E: Oscillation of solutions to odd-order nonlinear neutral functional differential equations. Electron. J. Differ. Equ. 2011, 23 (2011)

11. Li, T, Thandapani, E, Graef, JR: Oscillation of third-order neutral retarded differential equations. Int. J. Pure Appl. Math. 75, 511-520 (2012)

12. Li, T, Zhang, C, Xing, G: Oscillation of third-order neutral delay differential equations. Abstr. Appl. Anal. 2012, Article ID 569201 (2012). doi:10.1155/2012/569201

13. Philos, CG: Oscillation theorems for linear differential equations of second order. Arch. Math. 53, $482-492$ (1989)

14. Thandapani, E, Li, T: On the oscillation of third-order quasi-linear neutral functional differential equations. Arch. Math. (Brno) 47, 181-199 (2011)

15. Xing, G, Li, T, Zhang, C: Oscillation of higher-order quasi-linear neutral differential equations. Adv. Differ. Equ. 2011, 45 (2011)

16. Zhang, Q, Gao, L, Liu, S, Yu, Y: New oscillation criteria for third-order nonlinear functional differential equations. Abstr. Appl. Anal. 2014, Article ID 943170 (2014). doi:10.1155/2014/943170

10.1186/1029-242X-2014-512

Cite this article as: Jiang and Li: Asymptotic behavior of a third-order nonlinear neutral delay differential equation. Journal of Inequalities and Applications 2014, 2014:512 